\title{
Echocardiography in assessment of infants with complete d-transposition of great arteries
}

\author{
NIGEL M. BASS ${ }^{1}$, ANTONY H. G. ROCHE, PETER W. T. BRANDT, \\ AND JOHN M. NEUTZE
}

From the Departments of Cardiology and Radiology, Green Lane Hospital, Auckland, New Zealand

SUMMARY Echocardiography was performed prospectively in 43 infants with complete d-transposition of the great arteries (d-transposition), 29 of whom were in the first week of life. When the final diagnosis had been established an assessment was made of the reliability of the echocardiographic findings and their contribution to the clinical diagnosis.

The atrioventricular valves were correctly assessed in 40 infants and incorrectly in 3, the error being important in 1. The ventricular septum was recorded in 42 and failure to record a normal septum occurred in 1. Abnormal great arterial root positions were recorded by echocardiography in 35 of 43 infants, but minor variations in position could not be detected with accuracy. Assessment of the root positions was incomplete in 7 of 43 and incorrect in 1.

The great aterial root positions were determined by cineangiocardiography and showed pronounced variation, as also occurs in connection disorders other than d-transposition. The connection diagnosis, therefore, cannot be established by the demonstration of any particular root positions.

Echocardiography made a significant contribution to the clinical diagnosis of d-transposition in 35 of 43 infants $(81 \%)$, and the findings were incomplete in 5 of $43(12 \%)$. Seriously misleading information was provided in 3 of $43(7 \%)$.

Echocardiography aids management in the majority of infants with d-transposition and can help to exclude this condition in infants who are hypoxic from other causes.

Complete transposition of the great arteries is a potentially lethal condition and survival largely depends upon prompt diagnosis and treatment (Rowe and Vlad, 1973). The use of echocardiography in the recognition of transposition of the great arteries was first described by Gramiak et al. (1973), but since then there has been little objective information about its role in the management of this condition. Echocardiography can contribute to the clinical diagnosis in the majority of infants with transposition and this report describes our experience in a group of infants in whom echocardiography was performed prospectively.

The report is confined to patients with visceroatrial situs solitus, a concordant ventricular d-loop (right-sided right ventricle) and transposition of the great arteries (d-transposition). Transposition of the great arteries is present when the aorta arises solely or mainly from the morphologically right ventricle

1Senior Research Fellow of the National Heart Foundation of New Zealand.

Received for publication 20 April 1977 and the pulmonary artery solely or mainly from the morphologically left ventricle (Van Praagh et al., 1971). Brief mention is made of related conditions.

\section{Patients}

Between July 1974 and February 1977 echocardiograms were obtained in an unselected group of 180 infants aged less than 6 months who were admitted to Green Lane Hospital with suspected heart disease. Forty-three were subsequently shown to have d-transposition and form the basis of this report.

The age ranged from 6 hours to 17 weeks and there were 29 infants under 1 week. Echocardiograms were done and analysed as soon as possible after admission before establishment of the final diagnosis. No baby received sedation but the assistance of a nurse was available in all cases.

The diagnosis of d-transposition was established in all patients by cardiac catheterisation and biplane cineangiocardiography. In most patients contrast 
injections were made in both ventricles, and oblique views were recorded, but additional injection sites and other views were used where necessary. In addition surgical confirmation of the diagnosis was subsequently available in 27 cases and necropsy in 8. Anatomical details are shown in Table 1.

The clinical diagnosis was made in each case before echocardiography by a cardiologist (usually J.M.N.) and this was based upon the history, physical examination, 12-lead scalar electrocardiogram, and chest $x$-ray films. All echocardiograms were recorded by one of the authors (usually N.M.B.). In the first 23 cases echocardiograms were recorded without knowledge of the initial clinical assessment and in the last 20 cases they were recorded knowing the clinical assessment. This difference did not appear to influence results. After cardiac catheterisation and cineangiocardiographic studies a retrospective assessment was made in each case to determine whether or not the echocardiographic findings had contributed to the original clinical diagnosis.

\section{Method of echocardiography}

Echocardiograms were made with an Ekoline 20 echocardiograph. A 0.5 in $2.25 \mathrm{MHz}$ transducer focused to $10 \mathrm{~cm}$ was used in the first 13 cases and a 0.25 in $5.0 \mathrm{MHz}$ non-focused transducer was used in the remainder. Permanent records were made with polaroid film in the first 23 cases and with $35 \mathrm{~mm}$ photographic film strip records in the last 20 cases. An electrocardiogram was recorded with the echocardiogram only in selected cases.

Table 1 Anatomy in 43 infants with d-transposition of the great arteries

\begin{tabular}{lllr}
\hline $\begin{array}{l}\text { Classification } \\
\text { according to clinical } \\
\text { presentation }\end{array}$ & $\begin{array}{l}\text { No. of } \\
\text { infants }\end{array}$ & Associated cardiac anomalies \\
\hline (1) Poor mixing & 24 & Interatrial communication & 1 \\
& & Small PDA & 10 \\
& & Small VSD & 5 \\
Small VSD and PDA & 8 \\
(2) Free mixing & 13 & Large PDA & 6 \\
(3) VSD and PS & 4 & Large VSD & 1 \\
(4) Complex & 2 & VSD, CO Ao, and PDA & 2 \\
\hline
\end{tabular}

PDA, persistent ductus arteriosus; VSD, ventricular septal defect; PS, pulmonary stenosis; CO Ao, coarctation of aorta.

*Additional anomalies included cleft anterior mitral leaflet (1), single papillary muscle to mitral valve (1), partial anomalous pulmonary venous connection (2), pulmonary artery overriding the interventricular septum (2), aneurysm of the membranous septum (1), overriding tricuspid valve with underdevelopment of right ventricle and mitral valve (1), and hypoplastic aortic arch (1). Several other infants had probable minor anomalies of the left ventricular outflow and 2 developed significant subvalvar pulmonary stenosis some months after the study.
The echocardiographic examination of the intracardiac structures was made using the technique reported for normal neonates by Solinger et al. (1972). The tehnique for describing the orientation of the great arterial roots at the level of the semilunar valves followed the principles described by Gramiak et al. (1973). Routine attempts were made to scan from the anterior and posterior walls of the posterior great artery to the ventricular septum and anterior cusp of the left atrioventricular valve respectively.

When using polaroid film, the atrioventricular valves, ventricular septum, and arterial roots were classified as normal, abnormal, or absent, and abnormalities were described. When using photographic film strip records, measurements were made of the range of movement of the atrioventricular valves, the left ventricular dimension, and the dimension of the great arterial roots (at endsystole). Detailed measurements were not made of the right ventricular dimension or of the thickness of the ventricular septum and posterior left ventricular wall because it became apparent that detailed measurements frequently could not be repeated with confidence in sick infants without sedation.

\section{Results}

\section{INTRACARDIAC FINDINGS}

The echocardiographic assessment of normal right and left atrioventricular valves was correct in 40 of 43 infants. In one an overriding right atrioventricular valve shown by cineangiocardiography was mistaken in the echocardiogram for a left atrioventricular valve and the hypoplastic left atrioventricular valve in this infant was not recorded. One left atrioventricular valve classified as normal by echocardiography was found to have a single papillary muscle and another was found to have a cleft anterior leaflet; both were thought to function normally on clinical, haemodynamic, and cineangiocardiographic grounds. A scan from the left atrioventricular valve to the posterior wall of the posterior great artery, indicating probable mitralpulmonary continuity, was obtained in 36 of the 43 infants, and this was supported by cineangiocardiography in all. This scan could not be achieved in the other 7 infants but in only 3 of these was there cineangiocardiographic, surgical, or necropsy evidence of true mitral-pulmonary discontinuity.

The ventricular septum was recorded in $\mathbf{4 2}$ of 43 infants and in all the septum moved posteriorly in systole. However, echocardiography failed to detect the ventricular septum in 1 infant with simple d-transposition and intact ventricular septum, and 
this was an unexplained technical error leading to the false echocardiographic diagnosis of single ventricle.

\section{POSITIONS OF GREAT ARTERIAL ROOTS}

Table 2 shows the assessment of the great arterial positions in 43 infants with d-transposition by both cineangiocardiography (usually right and left anterior oblique views) and echocardiography. Their positions by cineangiocardiography were most often right-anterior aorta and left-posterior pulmonary artery, but other arrangements occurred frequently.

The right-anterior and left-posterior root positions were usually demonstrated as such by echocardiography (Fig. 1). Incomplete assessment occurred in 1 because of uncertain orientation and in another because only the abnormal left-posterior root was recorded.

Anteroposterior positions were usually considered right-anterior and left-posterior by echocardiography. Thus the relative positions in a leftright direction were not accurate by echocardiography though the root positions appeared abnormal. Incomplete assessment occurred in 1 because only the abnormal posterior root was recorded and in another the root positions were incorrectly assessed as right-posterior and left-anterior.

Side-side positions were usually considered rightanterior and left-posterior by echocardiography or the leftward great artery was not recorded. The relative distances of the great arteries from the chest wall were, therefore, not accurately assessed but, where both roots were seen, their positions appeared definitely abnormal. Where only one great arterial root was identified (always right-anterior) its position appeared abnormal.

Left anterior and right-posterior root positions were assessed correctly by echocardiography in 1 infant (Fig. 2) and incompletely in another in whom the severely hypoplastic right-posterior pulmonary artery was not recorded.
Table 3 shows measurements derived from strip records of the arterial roots, left atrium, atrioventricular valves, and left ventricular dimension in 17 infants with d-transposition. The pulmonary artery was approximately equal in dimension to the aorta in 4 and larger in the remainder, and the atrioventricular valves were normal in all. No infant in this group had pulmonary stenosis. The report that d-transposition is probable when both semilunar valves are recorded simultaneously (Dillon et al., 1973) was not supported (Fig. 3).

\section{CONTRIBUTION OF ECHOCARDIOGRAPHY \\ TO CLINICAL DIAGNOSIS}

In Table 4 the contribution of echocardiography is shown in relation to the initial clinical diagnosis. Though d-transposition was the primary clinical diagnosis in almost half the cases, other diagnoses were entertained in the remainder, and in 6 the

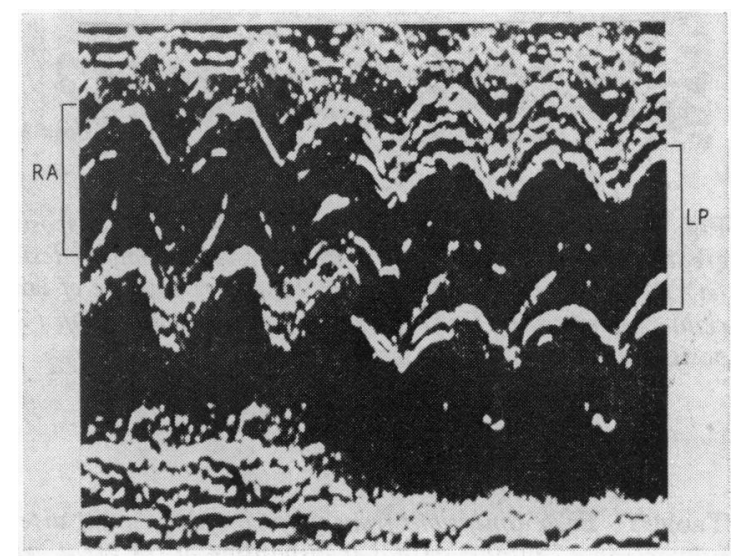

Fig. 1 Echocardiogram from a neonate with d-transposition of the great arteries showing the typical orientation of the great arterial roots. Right-anterior $(R A)$ and left-posterior (LP) arteries were recorded by a change of transducer angulation.

Table 2 Great arterial positions in 43 infants with d-transposition of the great arteries

\begin{tabular}{|c|c|c|c|c|c|c|c|}
\hline \multicolumn{2}{|c|}{ Cineangiocardiography } & \multicolumn{2}{|c|}{ Echocardiography } & Side-side & $L A, R P$ & Incomplete & Incorrect \\
\hline $\begin{array}{l}\text { RA, LP } \\
\text { AP } \\
\text { Side-side } \\
\text { LA, RP }\end{array}$ & $\begin{array}{c}23(53 \%) \\
11(26 \%) \\
7(16 \%) \\
2(5 \%)\end{array}$ & $\begin{array}{r}21 \\
8 \\
3 \\
-\end{array}$ & $\frac{-}{-}$ & $\frac{-}{1}$ & $\frac{-}{1}$ & $\begin{array}{l}2 \\
1 \\
3 \\
1\end{array}$ & $\frac{1}{-}$ \\
\hline
\end{tabular}

Note: 3 cases classified AP by cineangiocardiography were borderline RA, LP. 3 cases classified side-side by cineangiocardiography were borderline RA, LP.

*Usually right and left anterior oblique views.

RA, right-anterior; LP, left-posterior; AP, anteroposterior; LA, left-anterior; RP, right-posterior. 
primary clinical diagnosis was pulmonary atresia with normally-related great arteries. In conjunction with clinical findings echocardiography strongly supported the diagnosis of d-transposition in 33 patients and an important clinical alternative (single ventricle) was excluded in another 2 . On the other hand echocardiography was frankly misleading in 3 cases, in 1 because of incorrect assessment of the great arterial positions and in another because of failure to show the interventricular septum. The third case was complex with severe hypoplasia of the main pulmonary artery, an overriding tricuspid valve, and underdevelopment of the right ventricle and mitral valve. The atrioventricular valves were incorrectly assessed and the arterial roots incompletely assessed in this infant. Echocardiographic
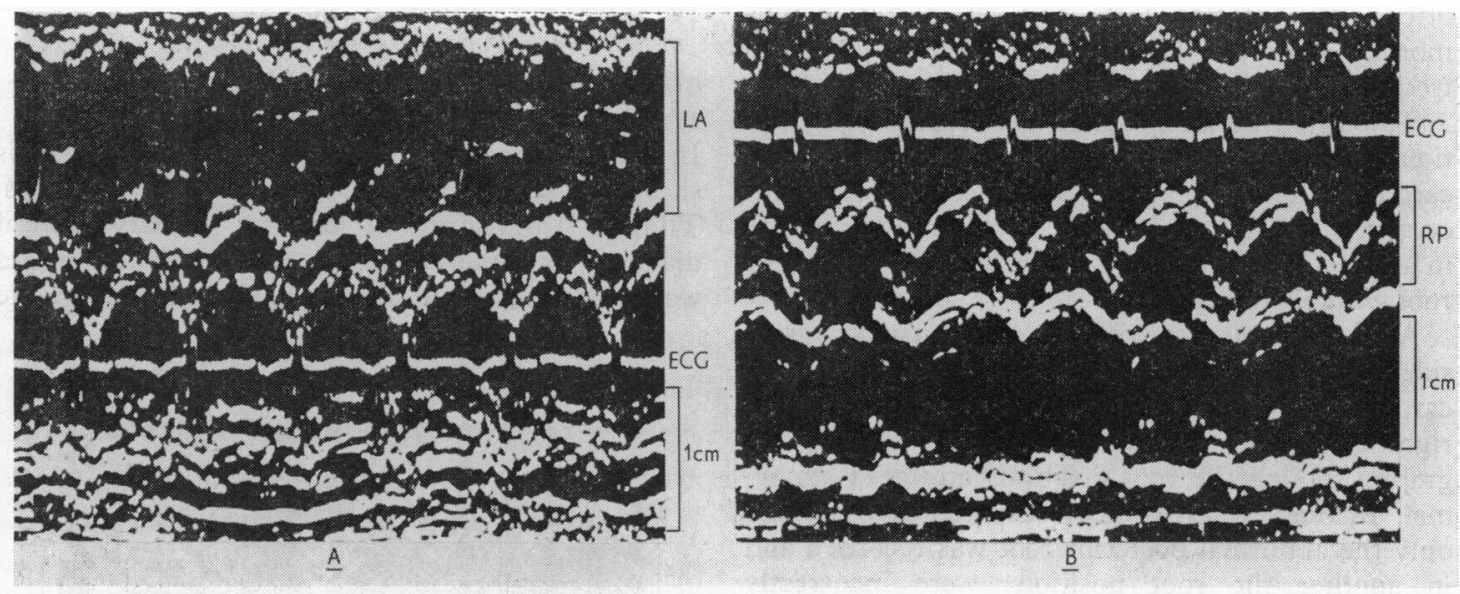

Fig. 2 Echocardiograms from a neonate with d-transposition of the great arteries and atypical orientation of the great arterial roots. Clinical signs suggested a complex lesion, with radiological evidence of reduced lung blood flow. (a) Record shows a left-anterior ( $L A$ ) arterial root of normal dimension $(13 \mathrm{~mm})$. (b) Record shows an abnormal right-posterior $(R P)$ arterial root of reduced dimension $(7 \mathrm{~mm})$. These findings were compatible with abnormallypositioned great arteries (see text).

Table 3 Echo dimensions from strip records of great arterial roots, left atrium, atrioventricular valves, and left ventricle in 17 infants with $d$-transposition of the great arteries

\begin{tabular}{|c|c|c|c|c|c|c|c|c|c|c|c|c|}
\hline $\begin{array}{l}\text { Infant } \\
\text { No. }\end{array}$ & $\begin{array}{l}\text { Age } \\
\text { (d) }\end{array}$ & $\begin{array}{l}W t \\
(k g)\end{array}$ & $V S D$ & Other lesion & $\begin{array}{l}\text { Great arte } \\
\text { positions } \\
\text { Echo }\end{array}$ & $\begin{array}{l}\text { Anial root } \\
\text { Angio }\end{array}$ & $\begin{array}{l}\text { Aorta } \\
(\mathrm{mm})\end{array}$ & $\begin{array}{l}\text { Pulmonary } \\
\text { artery } \\
\text { (min) }\end{array}$ & $\begin{array}{l}\text { Left } \\
\text { atrium } \\
(\mathrm{mm})\end{array}$ & $\begin{array}{l}\text { Right } A V \\
\text { valve- } \\
\text { range }(\mathrm{mm})\end{array}$ & $\begin{array}{l}\text { Left } A V \\
\text { valve- } \\
\text { range }(\mathrm{mm})\end{array}$ & $\begin{array}{l}\text { Left } \\
\text { ventricle } \\
\text { (mm) }\end{array}$ \\
\hline $\begin{array}{l}1 \\
2 \\
3 \\
4 \\
5 \\
6 \\
7 \\
8\end{array}$ & $\begin{array}{r}3 \\
1 \\
12 \\
2 \\
2 \\
1 \\
2 \\
77\end{array}$ & $\begin{array}{l}3 \cdot 2 \\
3 \cdot 6 \\
3 \cdot 2 \\
2 \cdot 5 \\
3 \cdot 9 \\
3 \cdot 9 \\
2 \cdot 7 \\
4 \cdot 1\end{array}$ & $\begin{array}{l}\text { - } \\
\overline{\text { Small }} \\
\overline{\text { Small }} \\
\overline{\text { Mod. }}\end{array}$ & $\begin{array}{l}\text { Mod. PDA } \\
\text { Small PDA } \\
\text { Large PDA } \\
\text { Small PDA } \\
\text { Small PDA } \\
\text { Small PDA } \\
\text { Large PDA } \\
\text { CO Ao, large PDA } \\
\text { and overriding PA }\end{array}$ & $\begin{array}{l}\text { RA, LP } \\
\text { RA, LP } \\
\text { side-side } \\
\text { RA, LP } \\
\text { RA, LP } \\
\text { RA, LP } \\
\text { AP } \\
\text { RA, LP }\end{array}$ & $\begin{array}{l}\text { RA, LP } \\
\text { AP } \\
\text { side-side } \\
\text { RA, LP } \\
\text { RA, LP } \\
\text { AP } \\
\text { AP } \\
\text { side-side }\end{array}$ & $\begin{array}{r}10 \cdot 8 \\
12 \cdot 2 \\
11 \cdot 7 \\
12.5 \\
11 \cdot 9 \\
10 \cdot 4 \\
10.9 \\
9 \cdot 3\end{array}$ & $\begin{array}{l}12 \cdot 5 \\
12 \cdot 4 \\
14 \cdot 5 \\
12 \cdot 2 \\
13 \cdot 0 \\
12 \cdot 3 \\
13 \cdot 0 \\
12 \cdot 8\end{array}$ & $\begin{array}{r}13 \cdot 3 \\
13 \cdot 0 \\
8 \cdot 8 \\
12 \cdot 0 \\
13 \cdot 9 \\
10 \cdot 5 \\
17 \cdot 4\end{array}$ & $\begin{array}{r}14 \cdot 5 \\
12 \cdot 3 \\
12 \cdot 4 \\
11 \cdot 6 \\
14 \cdot 6 \\
10 \cdot 0 \\
8 \cdot 5 \\
15 \cdot 7\end{array}$ & $\begin{array}{r}11 \cdot 1 \\
11 \cdot 8 \\
11 \cdot 3 \\
9 \cdot 8 \\
10 \cdot 6 \\
10 \cdot 3 \\
8 \cdot 8 \\
13 \cdot 0\end{array}$ & $\begin{array}{l}19 \cdot 5 \\
16 \cdot 6 \\
24 \cdot 6 \\
18.5 \\
20.5 \\
18.6 \\
20 \cdot 8 \\
25 \cdot 4\end{array}$ \\
\hline $\begin{array}{r}9 \\
10 \\
11 \\
12 \\
13 \\
14 \\
15 \\
16 \\
17\end{array}$ & $\begin{array}{r}3 \\
1 \\
4 \\
1 \\
4 \\
8 \\
1 \\
7 \\
35\end{array}$ & $\begin{array}{l}3 \cdot 3 \\
3 \cdot 3 \\
3 \cdot 1 \\
3 \cdot 1 \\
3 \cdot 6 \\
2 \cdot 5 \\
3 \cdot 9 \\
3 \cdot 4 \\
3 \cdot 6\end{array}$ & $\begin{array}{l}\text { Small } \\
\overline{\text { Mod. }} \\
\overline{\text { Small }} \\
\text { Small } \\
\text { Small } \\
\overline{\text { Small }}\end{array}$ & $\begin{array}{l}\text { Small PDA } \\
\text { Mod. PDA } \\
\overline{\text { Mod. PDA }} \\
\overline{\text { Small PDA }} \\
\text { Small PDA } \\
\text { Small PDA } \\
\text { Small PDA }\end{array}$ & $\begin{array}{l}\text { RA, LP } \\
\text { RA, LP } \\
\text { RA, LP } \\
\text { RA, LP } \\
\text { RA, LP } \\
\text { RA, LP } \\
\text { RA, LP } \\
\text { RA, LP } \\
\text { RA, LP }\end{array}$ & $\begin{array}{l}\text { AP } \\
\text { RA, LP } \\
\text { RA, LP } \\
\text { RA, LP } \\
\text { RA, LP } \\
\text { AP } \\
\text { AP } \\
\text { RA, LP } \\
\text { RA, LP }\end{array}$ & $\begin{array}{l}12 \cdot 1 \\
11 \cdot 5 \\
12 \cdot 1 \\
10 \cdot 4 \\
11 \cdot 7 \\
10 \cdot 0 \\
11 \cdot 1 \\
11 \cdot 1 \\
10.6\end{array}$ & $\begin{array}{l}12 \cdot 6 \\
13 \cdot 6 \\
14 \cdot 6 \\
11 \cdot 5 \\
11 \cdot 9 \\
12 \cdot 0 \\
11 \cdot 1 \\
14 \cdot 1 \\
14 \cdot 6\end{array}$ & $\begin{array}{r}15 \cdot 3 \\
15 \cdot 2 \\
13 \cdot 6 \\
13 \cdot 4 \\
11 \cdot 5 \\
11 \cdot 7 \\
8 \cdot 1 \\
13 \cdot 2 \\
14 \cdot 4\end{array}$ & $\begin{array}{l}13 \cdot 1 \\
13 \cdot 0 \\
11 \cdot 8 \\
11 \cdot 2 \\
11 \cdot 1 \\
13 \cdot 1 \\
12 \cdot 1 \\
11 \cdot 0 \\
12 \cdot 8\end{array}$ & $\begin{array}{r}10 \cdot 5 \\
10 \cdot 4 \\
10 \cdot 3 \\
9 \cdot 7 \\
9 \cdot 3 \\
10 \cdot 1 \\
9 \cdot 3 \\
9 \cdot 5 \\
12 \cdot 1\end{array}$ & $\begin{array}{l}20 \cdot 0 \\
21 \cdot 3 \\
22 \cdot 1 \\
16 \cdot 3 \\
22 \cdot 8 \\
18 \cdot 6 \\
15 \cdot 9 \\
21 \cdot 1 \\
29 \cdot 6\end{array}$ \\
\hline
\end{tabular}

VSD, ventricular septal defect; Echo, by echocardiography; Angio, by cineangiocardiography; AV, atrioventricular; PDA, persistent ductus arteriosus; RA, right-anterior; LP, left-posterior; $\mathbf{A P}$, anteroposterior; $C O$ Ao, coarctation of aorta; PA, pulmonary artery. 
findings were incomplete in another 5 infants because only 1 of 2 abnormal arterial roots was shown.

Thus echocardiography made a significant contribution to diagnosis in 81 per cent of cases, 78 per cent in the first half of the study using polaroid film for recording and 85 per cent in the latter half using photographic film strip recordings. We attribute the improved results mainly to greater experience, as they did not seem much influenced by knowledge of the clinical assessment and the use of photographic strip records in the later part of the study.
OTHER DIAGNOSES

There were 12 additional infants in whom the diagnosis of d-transposition was entertained clinically but in whom echocardiography showed the great arterial positions to be normal (Fig. 4 and 5). Four of these infants were hypoxic from noncardiac causes and required no further cardiac studies. In the remainder subsequent investigation excluded d-transposition and showed other complex cardiac anomalies, great arterial positions being normal in all.

There were another 6 infants whose great arteries were assessed by echocardiography as right-
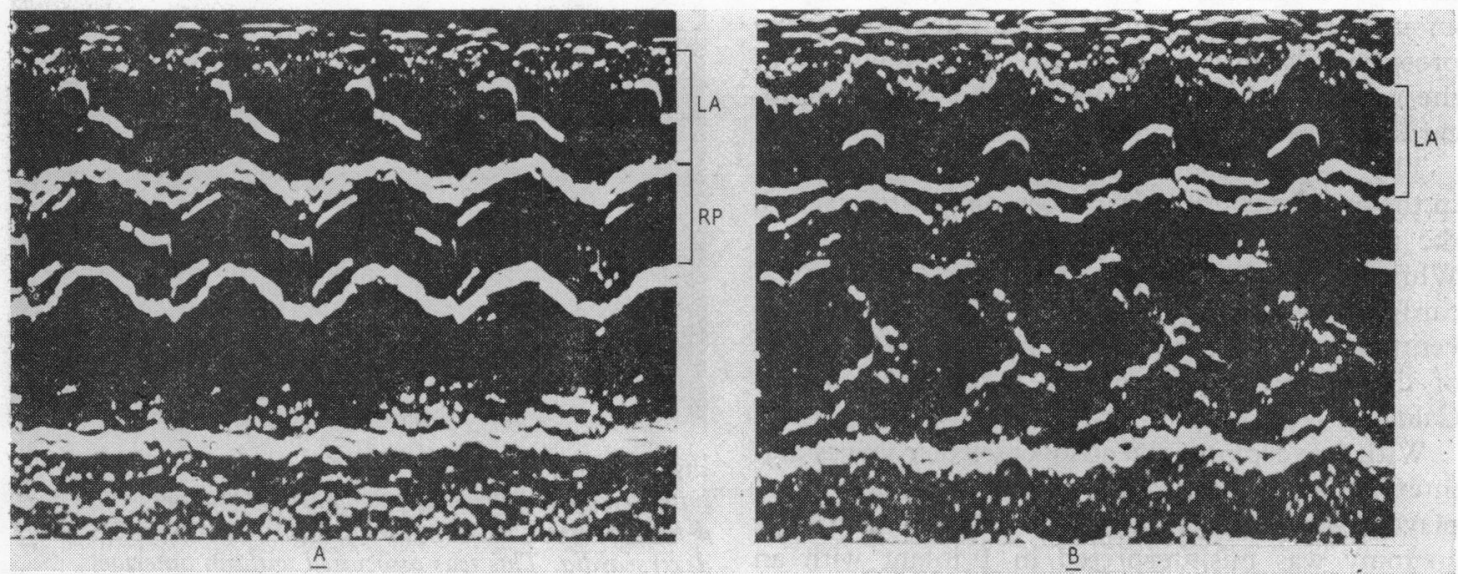

Fig. 3 Echocardiograms from a neonate with a persistent ductus arteriosus and normally-related great arteries. (a) Simultaneous recording of semilunar cusps of both the left-anterior ( $L A)$ and right-posterior (RP) arteries. Note that the anterior wall of the left anterior artery is not recorded. (b) Correct transducer angulation allows better recording of the $L A$ artery only.

Table 4 Assessment of contribution of echocardiography to clinical diagnosis in 43 infants with d-transposition of the great arteries

\begin{tabular}{|c|c|c|c|c|c|}
\hline \multirow[t]{2}{*}{ Clinical diagnosis } & \multirow{2}{*}{$\begin{array}{l}\text { No. of } \\
\text { infants }\end{array}$} & \multicolumn{4}{|c|}{ Echocardiographic contribution } \\
\hline & & TGA supported & $\begin{array}{l}\text { Important } \\
\text { alternative excluded }\end{array}$ & Echo incomplete & Echo misleading \\
\hline $\begin{array}{l}\text { (A) TGA probable } \\
\text { TGA only diagnosis } \\
\text { TGA most likely diagnosis } \\
\text { (B) TGA possible } \\
\text { TGA equal alternative diagnosis } \\
\text { TGA secondary diagnosis } \\
\text { (C) TGA unlikely } \\
\text { (clinical diagnosis pulmonary atresia) }\end{array}$ & $\begin{array}{r}21 \\
14 \\
7 \\
16 \\
10 \\
6 \\
6\end{array}$ & 18 & 一 & 2 & $\begin{array}{l}1 \\
\text { (IV septum not recorded) } \\
1 \\
\text { (Arterial roots misinterpreted) } \\
1 \\
\text { (AV valves and arterial roots } \\
\text { inadequately demonstrated) }\end{array}$ \\
\hline
\end{tabular}

Group A includes: 14 poor mixing, 6 free mixing, and 1 complex case.

Group B includes: 7 poor mixing, 6 free mixing, 2 VSD and PS, and 1 complex case.

Group $C$ includes: 3 poor mixing, 1 free mixing, and 2 VSD and PS.

TGA, transposition of the great arteries; IV, interventricular; AV, atrioventricular; VSD, ventricular septal defect; PS, pulmonary stenosis. 
anterior and left-posterior but who did not have d-transposition. In 3 of these the assessment was correct ( 2 with situs inversus and concordant l-transposition and one with double-outlet right ventricle). In the other 3 , all with complex anomalies, the echocardiographic assessment was incorrect.

\section{Discussion}

Our approach to the use and evaluation of echocardiography differs from that used in previous reports. Believing that the reliability of echocardiographic observations could not be judged impartially in patients with a known diagnosis, the echocardiograms were performed without knowing the final diagnosis. We have, therefore, attempted an unbiased evaluation of echocardiography done prospectively. We do not think that knowledge of the initial clinical assessment at the time of echocardiography in 20 infants affected this approach.

The use of single-transducer echocardiography in the assessment of d-transposition illustrates both the advantages and limitations of this technique. While it is excellent in displaying much of the intracardiac anatomy, it has limitations in displaying the ventriculoarterial connections on which the diagnosis of d-transposition should be based (Brandt and Calder, 1977).

With 2 exceptions the atrioventricular valves and interventricular septum were satisfactorily displayed by echocardiography. Atrioventricular valve anatomy was misinterpreted in 1 infant with an overriding tricuspid and a hypoplastic mitral valve, and the interventricular septum was not shown satisfactorily (even in retrospect) in another.

In the normal heart the aorta is right sided and posterior and the pulmonary artery is leftwards and anterior. The method of displaying abnormal

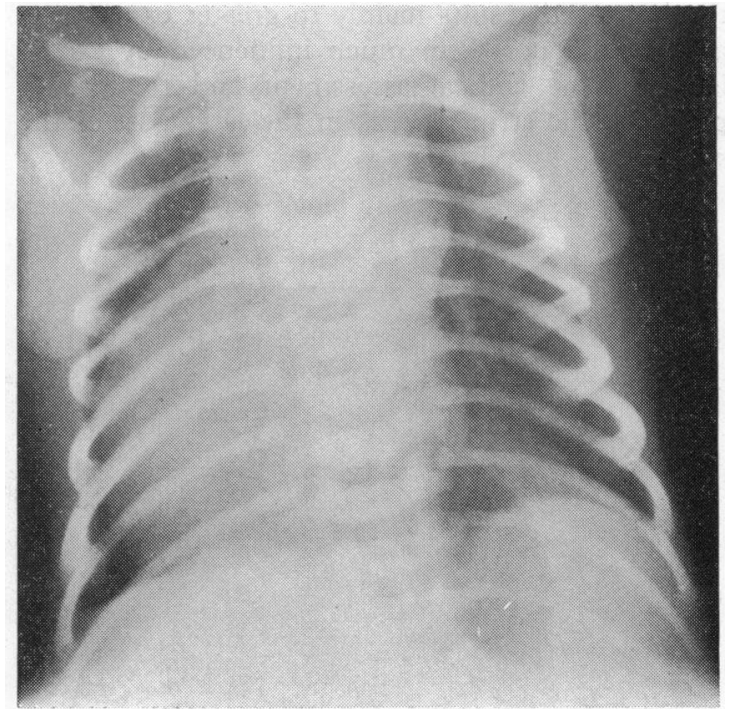

Fig. 4 Chest x-ray film of a mildly cyanosed 8-day-old infant in whom a complex anomaly, including $d$-transposition, was suspected. Film shows isolated dextrocardia. This was associated with an anterior diaphragmatic hernia.
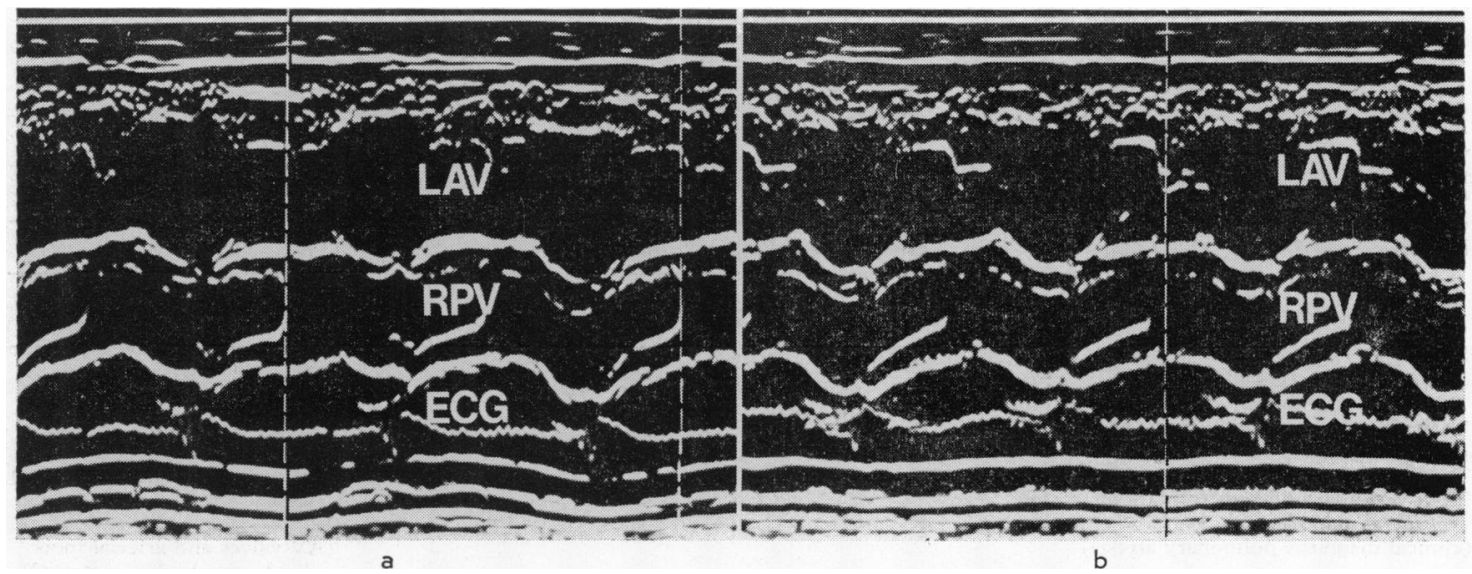

b

Fig. 5 Echocardiograms showing the timing of semilunar cusp closure in the infant whose chest $\mathrm{x}$-ray film is shown in Fig. 4. The vertical interrupted lines indicate the timing of closure of the semilunar cusps. (a) QRS closure time of the right-posterior semilunar valve (RPV) is $215 \mathrm{~ms}$. (b) $Q R S$ closure time of the left-anterior semilunar valve (LAV) is $226 \mathrm{~ms}$. These findings strongly support normally related great arteries (see text). 
arterial roots in d-transposition (Gramiak et al., 1973) relies upon the presence of the typical abnormal arrangement, a right-anterior aorta and left-posterior pulmonary artery (Fig. 1). However, previous studies using anteroposterior and lateral angiocardiography have shown this arrangement in only 69 per cent (Carr et al., 1968), and in 50 per cent of cases (Guerin et al., 1970). Similar findings occurred in the present study and the typical positions were shown by biplane cineangiocardiography with oblique views in 23 of $43(53 \%)$ infants with d-transposition. The classification of arterial positions can be somewhat arbitrary; the root positions in 6 cases classified either anteroposterior or sideside by cineangiocardiography were borderline right-anterior and left-posterior. The remaining cases showed pronounced variation in the relative positions of the great arterial roots, and it is obvious that the diagnosis of d-transposition cannot be made on the basis of these positions alone. Furthermore, though the finding of right-anterior and leftposterior arterial roots in an infant is strongly suggestive of d-transposition, it cannot be considered diagnostic by itself as this arrangement occurs in other conditions.

Abnormal arterial positions can be shown by echocardiography in most infants with d-transposition. The echocardiographic demonstration of right-anterior and left-posterior arterial roots supports a clinical diagnosis of d-transposition, though in some cases the actual positions may be anteroposterior and in others side-side. This difficulty in establishing the true relation of the root positions is presumably because of minor variations in transducer placement.

We regard the demonstration of right-anterior and left-posterior arterial roots, with the posterior wall of the posterior root continuous with the left atrioventricular valve on scanning, as strong supportive evidence for d-transposition. Because of variations in cardiac position, and in the development and rotation of the subaortic and subpulmonary coni, the echocardiographic identification of abnormal arterial root positions does not establish the connections of d-transposition, but in conjunction with other data it makes it probable. The echocardiographic findings must, therefore, be taken in conjunction with the clinical findings in d-transportion and, in this situation, our study has shown that echocardiography can provide additional information in at least 80 per cent of infants with this condition.

Echocardiography can still be useful when the positions of the great arterial roots are atypical. Fig. 2 shows the echocardiograms of a 3-day old infant with clinical signs suggesting a complex lesion and with evidence of reduced lung blood flow in the chest $x$-ray film. Echocardiography showed a normal-sized left-anterior arterial root and a right-posterior root of about two-thirds normal size, with the posterior wall of the posterior root in continuity with the left atrioventricular valve. In conjunction with the clinical and chest radiographic findings it could be deduced that the larger left-anterior root was likely to be the aorta, and that transposition or malposition of the great arteries was present. The final diagnosis was dtransposition with the left-anterior aorta arising from the right ventricle and the small right-posterior pulmonary artery arising from the left ventricle. As expected pulmonary stenosis was also present.

In passing it is of interest to note that we have examined 2 infants with situs inversus and concordant 1-transposition (the equivalent of dtransposition in situs solitus) in whom the great arterial roots were in a right-anterior and leftposterior position, not left-anterior and rightposterior as one might expect. We have also examined 2 infants with situs solitus and discordant 1-transposition. In 1 the great arterial positions were left-anterior and right-posterior as expected but they were anteroposterior in the other.

In the very young infant it may sometimes be difficult to distinguish clinically between $d-$ transposition and pulmonary atresia. The favoured clinical diagnosis in 6 infants in this study was pulmonary atresia (Table 4) and the echocardiographic demonstration in 4 of these infants of 2 arterial roots in the typical position was most helpful in supporting the diagnosis of d-transposition and excluding pulmonary atresia.

We have not found the simultaneous recording of both semilunar valves to be specific for d-transposition (Dillon et al., 1973), and we agree with others that this is a nonspecific finding (Paquet and Mullins, 1975; Hagler, 1976; Laird and Shelton, 1976). Fig. 3 illustrates this finding in a cyanosed premature infant with a persistent ductus arteriosus and normally-related great arteries. When the anterior wall of the left-anterior artery is properly recorded only the left-anterior semilunar valve is seen.

Recording of the timing of semilunar valve closure may increase the accuracy by identifying the arteries in many cases with d-transposition (Hirschfeld et al., 1975), but may not be reliable in the young infant (Hagler, 1976). We have not applied this technique routinely in infant studies: in the acute situation, when rapid conclusions were required before further investigation, it often proved impossible to record semilunar cusp closure ade- 
quately. It may, however, be a particularly useful aid to the identification of great arteries when the orientation of the heart is abnormal, as for example, in dextrocardia. Fig. 4 shows the chest $x$-ray film of a mildly cyanosed 8-day-old infant with dextrocardia associated with an anterior diaphragmatic hernia through the foramen of Morgagni, and in whom a complex cardiac anomaly including dtransposition was suspected clinically. Echocardiography showed normal atrioventricular valves, septum, and ventricular cavities, and the positions of the great arterial roots were right-posterior and left-anterior. The left atrioventricular valve was continuous with the posterior wall of the posterior great artery. The QRS closure time of the semilunar cusps was $11 \mathrm{~ms}$ longer for the anterior than for the posterior great artery (Fig. 5). These findings strongly supported normally-related great arteries and were against a complex anomaly. The final diagnosis was situs solitus with secondary dextrocardia, ventricular d-loop, large atrial septal defect, and small muscular ventricular septal defect.

The dimension of the posterior pulmonary artery in d-transposition is usually larger than that of the anterior aortic root (Solinger et al., 1973) and this was so in our study (Table 3). A small posterior root may, however, indicate the presence of $d$ transposition with pulmonary stenosis (Godman et al., 1974), and the relative sizes of the arterial roots do not prove their identity. A small aorta might indicate the presence of aortic stenosis or coarctation of the aorta, and it is interesting to note that the smallest aortic dimension in Table 3 was associated with severe coarctation of the aorta. We have not been able to predict the presence of a ventricular septal defect or persistence ductus arteriosus from the echocardiographic findings. Admittedly we have made few measurements of left atrial size in patients with free communications but there was no trend to a larger diameter in those measured. Nor have we seen abnormal left atrioventricular valve movement, indicating left ventricular outflow obstruction (Nanda et al., 1975), in young infants. One infant, however, had developed obstruction because of this mechanism (similar to that seen in idiopathic hypertrophic subaortic stenosis) by 6 months of age.

Echocardiography in the infant is a demanding discipline and its proper use requires an appreciation of its limitations as well as its advantages. Establishing the great arterial positions depends on the judgement of the direction of the transducer beam at the time of the examination and this is not infallible. Most incomplete echocardiographic assessments occurred early in the study. However, there are still occasions when it has been technically impossible to derive all information, and the unexplained failure to record satisfactorily the normal ventricular septum in one infant and a pulmonary arterial root of good size in another occurred later in the series. All negative echocardiographic observations, particularly in the presence of a complex cardiac anomaly, should therefore be regarded with reservation.

Atypical bilateral conal development may occur in 6 per cent of cases with d-transposition (Van Praagh et al., 1971) and these cases would be expected to show displacement of the left atrioventricular valve from the posterior wall of the posterior arterial root. Satisfactory scans supporting a close left atrioventricular valve-posterior root relation were recorded in 84 per cent of infants in this study. However, there was true left atrioventricular valve-posterior root discontinuity in only 3 of the 7 infants in whom this scan was not achieved. It was technically impossible to scan from the left atrioventricular valve to the posterior root in the other 4 though they were closely related.

The advantages of continuous strip records over polaroid films are obvious (Godman et al., 1974), but we do not consider the latter without value. It is not feasible to record the timing of semilunar cusp closure with polaroid film and records of the various dimensions and scans are less satisfactory. However, polaroid records do give rapid information about the atrioventricular valves, septum, and great arterial roots which is useful in the evaluation of d-transposition.

This study indicates that echocardiography adds significant information to the clinical assessment in over 80 per cent of infants with d-transposition without exposing them to risk or discomfort. On the other hand the technique requires expertise and time and, as the infants still require cardiac catheterisation, it may be questioned whether or not the contribution of echocardiography is sufficient to justify its use. We believe it is because a better appreciation of the intracardiac anomaly allows catheterisation to proceed more speedily and efficiently, and helps to direct angiocardiography along the most informative lines, minimising the insult to the infant. The same advantage applies to those patients in whom d-transposition is unlikely but cannot be excluded on clinical grounds. In those with hypoxia from non-cardiac causes cardiac catheterisation can usually be avoided, and in those with complex lesions echocardiographic information is helpful during the catheter study.

Real-time two-dimensional imaging has made a significant advance in the elucidation of ventriculoarterial connections (Henry et al., 1975; Maron et al., 1975). However, until this becomes more 
readily available, the single-transducer technique should contribute significantly to the early management of at least 80 per cent of infants with dtransposition.

This study has been supported by the National Heart Foundation of New Zealand.

\section{References}

Brandt, P. W. T., and Calder, A. L. (1977). Cardiac connections: the segmental approach to radiological diagnosis in congenital heart disease. Current Problems in Diagnostic Radiology. In press.

Carr, I., Tynan, M., Aberdeen, E., Bonham-Carter, R. E., Graham, G., and Waterston, D. J. (1968). Predictive accuracy of the 'loop-rule' in 109 children with classical complete transposition of the great arteries (TGA) (abstract). Circulation, 38 Suppl. VI, 52.

Dillon, J. C., Feigenbaum, H., Konecke, L. L., Keutel, J., Hurwitz, R. A., Davis, R. H., and Chang, S. (1973). Echocardiographic manifestations of d-transposition of the great vessels. American fournal of Cardiology, 32, 74-78.

Godman, M. J., Tham, P., and Langford Kidd, B. S. (1974). Echocardiography in the evaluation of the cyanotic newborn infant. British Heart Fournal, 36, 154-166.

Gramiak, R., Chung, K. J., Nanda, N., and Manning, J. (1973). Echocardiographic diagnosis of transposition of the great vessels. Radiology, 106, 187-189.

Guerin, R., Soto, B., Karp, R. B., Kirklin, J. W., and Barcia, A. (1970). Transposition of the great arteries. Determination of the position of the great arteries in conventional chest roentgenograms. American fournal of Roentgenology, 110, 747-756.

Hagler, D. J. (1976). The utilization of echocardiography in the differential diagnosis of cyanosis in the neonate. Mayo Clinic Proceedings, 51, 143-154.

Henry, W. L., Maron, B. J., Griffith, J. M., Redwood, D. R., and Epstein, S. E. (1975). Differential diagnosis of anomalies of the great arteries by real-time two-dimensional echocardiography. Circulation, 51, 283-291.

Hirschfeld, S., Meyer, R., Schwartz, D. C., Korfhagen, J., and Kaplan, S. (1975). Measurement of right and left ventricular systolic time intervals by echocardiography. Circulation, 51, 304-309.

Laird, W. P., and Shelton, S. L. (1976). Simultaneous echocardiographic recording of semilunar valves in patients with normally related great arteries. Radiology, 118, 397-400.

Maron, B. J., Henry, W. L., Griffith, J. M., Freedom, R. M., Kelly, D. T., and Epstein, S. E. (1975). Identification of congenital malformations of the great arteries in infants by real-time two-dimensional echocardiography. Circulation, 52, 671-677.

Nanda, N. C., Gramiak, R., Manning, J. A., and Lipchik, E. O. (1975). Echocardiographic features of subpulmonic obstruction in dextro-transposition of the great vessels. Circulation, 51, 515-521.

Paquet, M., and Mullins, C. E. (1975). Echocardiogram in d-transposition of great vessels (letter). American fournal of Cardiology, 36, 121.

Rowe, R. D., and Vlad, P. (1973). Diagnostic problems in the newborn. Origins of mortality in congenital cardiac malformation. In Heart Disease in Infancy, pp. 8-19. Ed. B. G. Barratt-Boyes, J. M. Neutze, and E. A. Harris. Churchill Livingstone, Edinburgh and London.

Solinger, R., Elbl, F., and Minhas, K. (1972). Echocardiography in the normal neonate. Circulation, 47, 108-118.

Solinger, R., Elbl, F., and Minhas, K. (1973). Echocardiographic features of complete transposition of the great vessels in infancy (abstract). American fournal of Cardiology, 31, 158.

Van Praagh, R., Pérez-Treviño, C., López-Cuellar, M., Baker, F. W., Zuberbuhler, J. R., Quero, M., Perez, V. M., Moreno, F., and Van Praagh, S. (1971). Transposition of the great arteries with posterior aorta, anterior pulmonary artery, subpulmonary conus and fibrous continuity between aortic and atrioventricular valves. American fournal of Cardiology, 28, 621-631.

Requests for reprints to $\mathrm{Dr}$ Nigel $M$. Bass, Cardiology Unit, Green Lane Hospital, Green Lane West, Auckland 3, New Zealand. 